\title{
EPIDEMIOLOGICAL AND PATHOLOGICAL STUDIES OF GALLSTONE DISEASE IN PATIENTS OF LUCKNOW REGION
}

\author{
Abha Misra1 ${ }^{1}$ Ritu Sharma², Manaswi Chaubey 3 , Rajesh Kr. Chaturvedi ${ }^{4}$ \\ ${ }_{1}^{1}$ Assistant Professor, Department of Pathology, TSM Medical College, Lucknow, Uttar Pradesh. \\ ${ }^{2}$ Assistant Professor, Department of Pathology, TSM Medical College, Lucknow, Uttar Pradesh. \\ ${ }^{3}$ Assistant Professor, Department of Medicine, IMS-BHU, Varanasi, Uttar Pradesh. \\ ${ }^{4}$ Professor and HOD, Department of Forensic Medicine and Toxicology, TSM Medical College, Lucknow, Uttar Pradesh. \\ ABSTRACT
}

\section{BACKGROUND}

Gallstone disease is the most common gastrointestinal problem associated with gallbladder affecting millions of people throughout the world. The gallstones are solid crystalline precipitates in the biliary tract, usually formed in the gallbladder. Cholesterol and calcium bilirubinate are the two main substances involved in gallstone formation. Based on their chemical composition, gallstones are classified as cholesterol, pigment and mixed stones.(1) The colour of gallstones may be white, yellow, brown, black and green. Cholesterol stones are usually yellow, but are sometimes white in colour. Mixed stones are usually smaller, multiple in numbers and occur in various colours and shapes. Pigment gallstone may be brown or black, which mainly consists of bilirubin and calcium salts such as calcium carbonate.(2) The incidence of this disease shows substantial geographical variation with higher incidence in North Indian people as compared to South Indian people.(3) Dietary habits and lifestyle of the patient are going to influence the formation of gallstone.(4) High biliary protein and lipid concentration are risk factors for the formation of gallstones, while gallbladder sludge is thought to be usual precursor of gallstone formation. Age, gender and ethnicity are the most important factors predisposing its prevalence in population.(5) Gallstone disease is related to several cardiometabolic risk factors such as obesity, dyslipidaemias (Hypertriglyceridaemia and low-high-density lipoprotein and high cholesterol), diabetes, unhealthy diet and sedentary lifestyle. High-risk factor for the cholesterol dominant gallstones is the obese individuals with a body mass index of 30 $\mathrm{kg} / \mathrm{sq}$. metre.(6) People with diabetes are at higher risk for gallstone disease and gallbladder disease may progress more rapidly in patients with diabetes who are obese and tend to have infection.(7)

This study was aimed to confirm the prevalence of various types of gallstones in rural population of Lucknow region with concern to most common age group and sex including common clinical features manifested during the course of the disease.

\section{MATERIALS AND METHODS}

This study is a retrospective descriptive study, which included 132 patients over a period of 18 months (from July 2015 to December 2016) with diagnosis based on abdominal ultrasound report and further confirmed by biochemical test. Detailed history of all patients was taken with reference to dietary habits, age, sex and metabolic diseases (Diabetes) and lab reports from MR department. These cases were systematised to find out the cumulative prevalence rate of gallstone disease among rural population of Lucknow region, because TSM Hospital caters services mostly to rural patient. Previous records of abdominal ultrasound were reviewed, which were available in MR department of hospital during July 2015 to December 2016. Data was tabulated separately and cases for positive and negative for gallstones disease were identified and gallstones of patients available in pathology department were further analysed with chemical and enzymatic methods for knowing types of gallstones prevalent in this area.

\section{RESULTS}

A total of 132 patients with gallstone disease were diagnosed by abdominal ultrasound. The most interesting finding of this present study was that gallstone disease was more common in females (79.54\%) as compared to males (20.45\%) in ratio of female-to-male as 3.88: 1 . The age of cases was considered from newborn to 70 years. The observations were grouped after every 10 years interval. In 0 - 10 age group, $1(0.75 \%)$ case of gallstone disease was reported. Maximum cases (43.94\%) were reported in 41 - 50 age group. We noticed 2 (1.5\%) cases in 11 - 20 age group, 17 (12.8\%) cases in 21 - 30 age group, 30 (22.73\%) in 31 - 40 age group, $20(15.15 \%)$ in 51 - 60 age group and $4(3.03 \%)$ in 61 - 70 age group. The disease has huge incidence in the age group of $41-50$ years. The common complication was flatulence (64), dyspepsia (63), epigastric pain (49) and pain in right hypochondrium (47) and 37 patients had complaints of nausea also. The biliary calculi collected from 132 patients were divided into 3 groups based on their colour: Cholesterol calculi, Mixed calculi and Pigment calculi. Out of 132 stones 50 (37.87\%) were cholesterol, 47 (35.60\%) were mixed stone and $35(26.51 \%)$ were pigment stone indicating incidence of gallstones in the studied population from this area as Cholesterol stone $>$ mixed stone $>$ pigment stone. 18 out of 132 were known diabetics under this study. This reflects association of metabolic disease (Diabetes) with gallstone disease in Indian population.

\section{CONCLUSION}

Gallstone disease is more prevalent in female patients and has higher incidence as compared to male patient. Gallstone disease is more common in 41 to 50 years' age group. The most common type of gallstones was found to be cholesterol type of gallstone followed by mixed and pigment gallstone. In spite of numerous well-defined risk factors for gallstone, global epidemic of obesity and metabolic syndrome will probably increase incidence of gallstone disease in population.

\section{KEY WORDS}

AC- Acute Cholecystitis, USG- Ultrasonography, LDL- Low Density Lipoprotein. 
HOW TO CITE THIS ARTICLE: Misra A, Sharma R, Chaubey M, et al. Epidemiological and pathological studies of gallstone disease in patients of Lucknow region. J. Evolution Med. Dent. Sci. 2018;7(20):2498-2501, DOI: 10.14260/jemds/2018/561

\section{BACKGROUND}

Gallstone disease is the most common gastrointestinal problem associated with gallbladder affecting millions of people throughout the world. The gallstones are solid crystalline precipitates in the biliary tract usually formed in the gallbladder. Cholesterol and calcium bilirubinate are the two main substances involved in gallstone formation.

People with diabetes are at higher risk for gallstone disease and gallbladder disease may progress more rapidly in patients with diabetes who are obese and tend to have infection. (7)

This study was aimed to confirm the prevalence of various types of gallstones in rural population of Lucknow region with concern to most common age group and sex including common clinical features manifested during the course of the disease.

\section{MATERIALS AND METHODS}

This study is a retrospective descriptive study, which included 132 patients over a period of 18 months (From July 2015 to December 2016) with diagnosis based on abdominal ultrasound report and further confirmed by biochemical test. Detailed history of all patients was taken with reference to dietary habits, age, sex and metabolic diseases (Diabetes) and lab reports from MR department. These cases were systematised to find out the cumulative prevalence rate of gallstone disease among rural population of Lucknow region, because TSM hospital caters services mostly to rural patient. Previous records of abdominal ultrasound were reviewed, which were available in MR department of hospital during July 2015 to December 2016. Data was tabulated separately and cases for positive and negative for gallstones disease were identified and gallstones of patients available in pathology department were further analysed with chemical and enzymatic methods for knowing types of gallstone prevalent in this area.

\section{RESULTS}

The incidence of gallstones is more common in female cases,(7) because female sex hormones and dietary habits of most women in India exposes them to factors that probably promote the formation of gall stones. ${ }^{(8)}$

In our present study, maximum cases were in the age group of 41 - 50 which is little bit earlier than mentioned age group. Furthermore, studies reported by Priyesh Halgaonker et al(9) and Maclure KM et al, the peak age of occurrence were 31 - 40 and 45 - 59 years. (10)

Our study concluded that gallstones are more prevalent in female as compared to males with ratio of 3.88: 1 . This finding is consistent with the study done by Sachedeva et al.(11)

'Financial or Other Competing Interest': None.

Submission 09-03-2018, Peer Review 30-04-2018,

Acceptance 07-05-2018, Published 14-05-2018.

Corresponding Author:

Ritu Sharma,

Assistant Professor,

Department of Pathology,

TSM Medical College, Lucknow, Uttar Pradesh.

E-mail: drritzsharma@gmail.com

DOI: $10.14260 /$ jemds $/ 2018 / 561$

\section{(c) (1) $(9)$}

It was found under this study that $37.87 \%$ had cholesterol stone, $35.60 \%$ mixed stone and $26.51 \%$ pigment stone which are in accordance with the studies carried out by Barbara et al.(12)

$13.63 \%$ cases were known diabetics associated with gallstone disease in this study. This reflects association of metabolic disease with this disease and studies of BA Chapman et al also confirmed increased incidence of gallstones in diabetic patient.

Patients with diabetes are generally overweight and obesity is linked to gallstone disease. They have higher levels of triglycerides and it is known that the triglycerides themselves encourage gallstone formation.

\begin{tabular}{|c|c|c|}
\hline Sex & Total No. of Cases & Percentage (\%) \\
\hline Male & 27 & $20.45 \%$ \\
\hline Female & 105 & $79.54 \%$ \\
\hline Total & $\mathbf{1 3 2}$ & $\mathbf{1 0 0 \%}$ \\
\hline
\end{tabular}

Table 1. Sex Wise distribution of Gallstone in Patient

\begin{tabular}{|c|c|c|}
\hline Age Group & Total No. of Cases & Percentage (\%) \\
\hline $0-10$ & 01 & $0.75 \%$ \\
\hline $11-20$ & 02 & $1.5 \%$ \\
\hline $21-30$ & 17 & $12.88 \%$ \\
\hline $31-40$ & 30 & $22.73 \%$ \\
\hline $41-50$ & 58 & $43.93 \%$ \\
\hline $51-60$ & 20 & $15.15 \%$ \\
\hline $61-70$ & 04 & $3.03 \%$ \\
\hline Total & 132 & $100 \%$ \\
\hline
\end{tabular}

\begin{tabular}{|c|c|}
\hline Sign/ Symptom & Frequency \\
\hline Epigastric pain & 49 \\
\hline Pain in right hypochondrium & 47 \\
\hline Nausea & 37 \\
\hline Dyspepsia & 63 \\
\hline Flatulence & 64 \\
\hline
\end{tabular}

\begin{tabular}{|c|c|c|}
\hline Type of Stone & Stone Frequency & Percentage (\%) \\
\hline Cholesterol Stone & 50 & 37.87 \\
\hline Mixed Stone & 47 & 35.60 \\
\hline Pigment Stone & 35 & 26.51 \\
\hline Total & 132 & $100 \%$ \\
\hline
\end{tabular}

\begin{tabular}{|c|c|c|}
\hline Feature & Total No. of Cases & Percentage (\%) \\
\hline Diabetic & 18 & $13.64 \%$ \\
\hline Non-Diabetic & 114 & $86.36 \%$ \\
\hline Total & $\mathbf{1 3 2}$ & $\mathbf{1 0 0 \%}$ \\
\hline \multicolumn{2}{|c|}{ Table 5. Prevalence of Gallstone among Diabetes Type-2 } \\
Patients \\
\hline
\end{tabular}




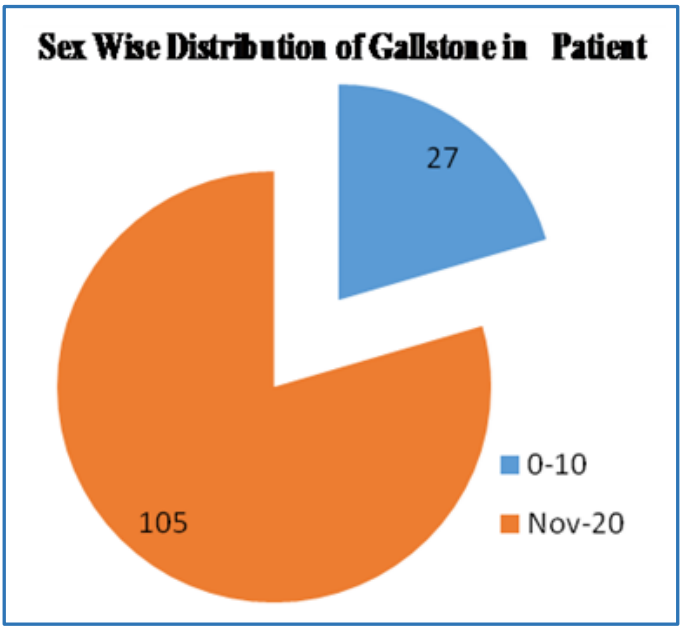

Types of Gallstone according to Composition

\section{Stone Frequency}
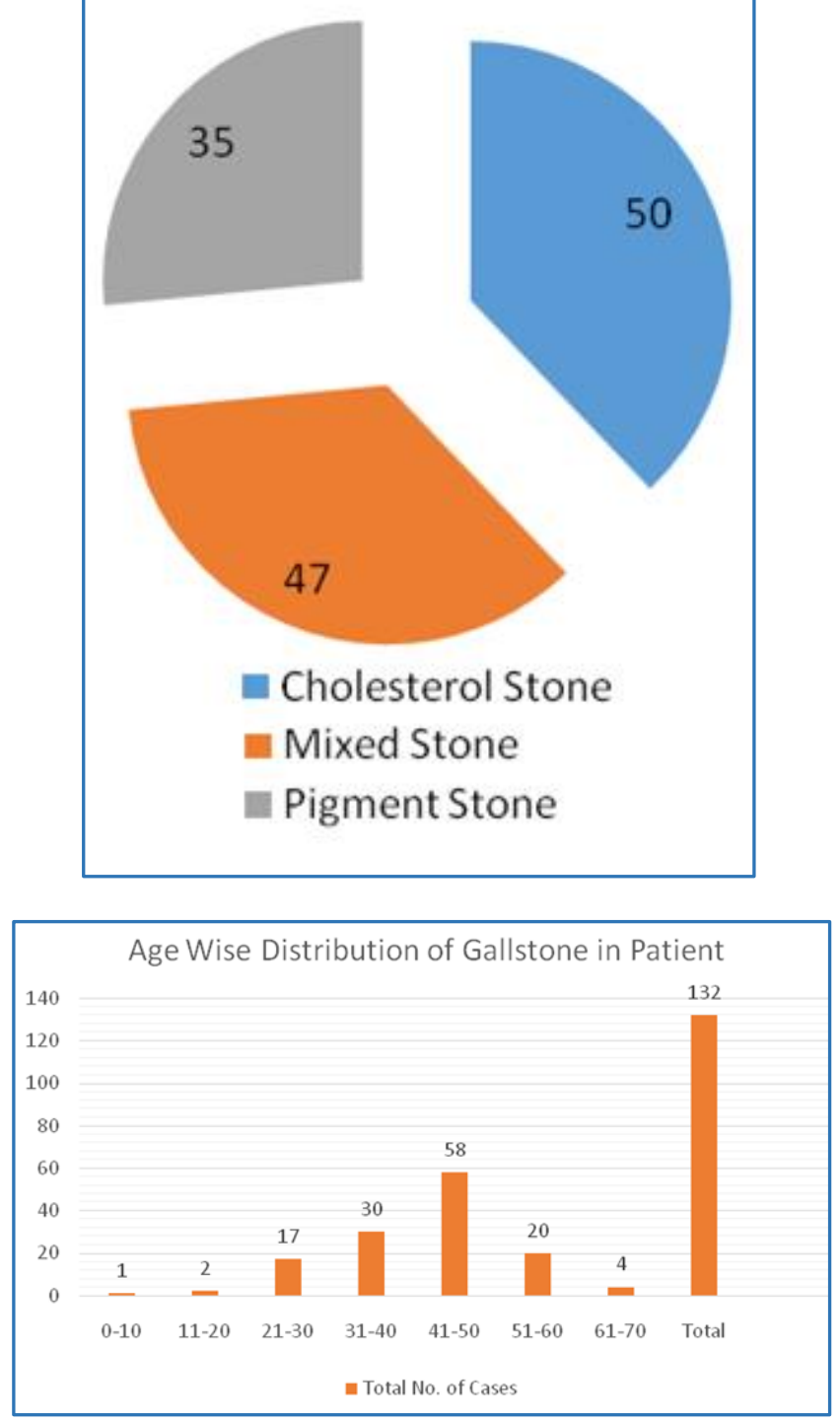

\section{DISCUSSION}

Our study included a total of 132 gallstone patients, all of which underwent cholecystectomy in hospital. Gallstone available and kept in pathology department were subjected to chemical analysis for the presence of cholesterol, bilirubin, calcium and phosphate. Gallstone disease represents a major medical problem in Lucknow region. The incidence of gallstone disease is most often correlated with socioeconomic condition and dietary habits. Conventionally, stones were classified into three categories namely cholesterol stones, mixed stones and pigment stones. The incidence of gallstones is more common in female cases.(7) Because female sex hormones and dietary habits of most women in India exposes them to factors that probably promote the formation of gall stones. ${ }^{(8)}$

In our present study maximum cases were in the age group of $41-50$, which is little bit earlier than mentioned age group. Furthermore, studies reported by Priyesh Halgaonker et al(9) and Maclure KM et al, the peak age of occurrence were 31 - 40 and 45 - 59 years.(10) Our study concluded that gallstones are more prevalent in females as compared to male with ratio of 3.88: 1 . This finding is consistent with the study done by Sachedeva et al.(11) It was found under this study that $37.87 \%$ had cholesterol stone, $35.60 \%$ mixed stone and $26.51 \%$ pigment stone which are in accordance with the studies carried out by Barbara et al.(12) $13.63 \%$ cases were known diabetic associated with gallstone disease in this study. This reflects association of metabolic disease with this disease and studies of BA Chapman et al also confirmed increased incidence of gallstones in diabetic patient. Patient with diabetes are generally overweight and obesity is linked to gallstone disease. They have higher levels of triglycerides and it is known that the triglycerides themselves encourage gallstone formation.(13) Another theory is that stones form because of what is called autonomic neuropathy or damage from diabetes to the involuntary nerves that control movement of the bowels and gallbladder. According to this line of thought the bile stored in the gallbladder is not released efficiently, because the nerves are damaged and gallstones form from the resulting sludge.(14) Also, recent research on insulin-resistant mice shows that FOX01, a specific protein involved with diabetes, increases the amount of cholesterol that enters the bile which may lead to the formation of gallstones.(15)

\section{CONCLUSION}

Gallstone disease is more prevalent in female patients and has higher incidence as compared to male patient. Gallstone disease is more common in 41 to 50 years' age group. The most common type of gallstones was found to be cholesterol type of gallstone followed by mixed and pigment gallstone. In spite of numerous well-defined risk factors for gallstone, global epidemic of obesity and metabolic syndrome will probably increase incidence of gallstone disease in population.

\section{REFERENCES}

[1] Ananthakrishnan N. Current concepts in the pathogenesis of gallstones. Indian Journ of Surg 1998;60:85-9.

[2] Sarin SK, Kapur BM, Tandon RK. Cholesterol and pigment gallstones in northern India. A prospective analysis. Dig Dis Sci 1986;31(10):1041-5.

[3] Khuroo MS, Mahajan R, Zargar SA, et al. Prevalence of biliary tract disease in India: a sonographic study in adult population in Kashmir. Gut 1989;30(2):201-5. 
[4] Rathnaswami A, Vijayan J, Omprakash R, et al. Gallstone diseases - our experience. South Indian Journal Clinics 1989;3:89-93.

[5] Agarwal DK, Choudhari G, Rao KV, et al. Gallstone composition in North India population changing pattern (abs). Indian J Gastroenterol 1991;10: A14.

[6] Trotman BW, Soloway RD. Pigment vs cholesterol cholelithiasis: clinical and epidemiological aspects. Am J Dig Dis 1975;20(8):735-40.

[7] Sodhi JS, Zargar SA, Khateeb S, et al. Prevalence of gallstone disease in patients with type 2 diabetes and the risk factors in North Indian population: a case control study. Indian Journal of Gastroenterology 2014;33(6):507-11.

[8] Jayanthi V. Pattern of gallstone disease in Chennai city, South India - a hospital based survey. The Journ Assoc Physicians of India 1996;44(7):461-4.

[9] Halgaonkar P, Verma R, Bhadre R, et al. Study to establish the clinical correlation between chemical constituents of gallstones and serum biochemical parameters. International Journal of Scientific Study 2016;4(3):97-102.
[10] Maclure KM, Hayes KC, Colditz GA, et al. Weight, diet and the risk of symptomatic gallstones in middle-aged women. N Engl J Med 1989:321(9):563-9.

[11] Sachedeva S, Khan Z, Ansari MA, et al. Life style and gallstone disease: scope for primary prevention. Indian Journal of Community Medicine 2011;36(4):263-7.

[12] Barbara L, Sama C, Labate AMM, et al. Population study on the prevalence of gallstone disease: the Sirmione study. Hepatology 1987;7(5):913-7.

[13] Lee SX, Heine M, Schlein C, et al. FoxO transcription factors are required for hepatic HDL cholesterol clearance. J Clin Invest 2018;128(4):1615-26.

[14] Gaur C, Mathur A, Agarwal A, et al. Diabetic autonomic neuropathy causing gall bladder dysfunction. J Assoc Physicians India 2000;48(6):603-5.

[15] Ponugoti B, Dong G, Graves DT, Role of forkhead transcription factors in diabetes-induced oxidative stress. Experimental Diabetes Research 2012;2012:939751. 